\title{
90. Two new Fatty Acids obtained from Fish Oils (On the Separation of Glycerides Part XV).
}

\author{
By Bunsuke Suzuki and Yoshikuni YoKoyama.
}

(Comm. by U. SuzUkI, M.I.A., July 12, 1929.)

1. $\mathrm{C}_{22} \mathrm{H}_{36} \mathrm{O}_{2}$. A new acid the bromide of which melted at $96^{\circ} \mathrm{C}$. was obtained from herring as well as sardine oil as shown in a paper which is to be published elsewhere in this number of the Proceedings. No acid the bromide of which has the same melting point is found in current literature. The experimental formula calculated from its bromine content is either $\mathrm{C}_{22} \mathrm{H}_{36} \mathrm{O}_{2} \mathrm{Br}_{8}(\mathrm{Br}: 65.80 \%)$ or $\mathrm{C}_{16} \mathrm{H}_{26} \mathrm{O}_{2} \mathrm{Br}_{6}(\mathrm{Br}: 65.71 \%)$. In order to decide which is the case with the new acid, the brominated acid was debrominated by the ususal method and the resultant acid was submitted to the hydrogenation in the presence of platinum black using amyl ether as the solvent. The saturated acid, thus obtained, melted at $78^{\circ} \mathrm{C}$. and the result of elementary analysis has shown that it is nothing other than behenic acid.

2. $\mathrm{C}_{18} \mathrm{H}_{28} \mathrm{O}_{2}$. Another new acid was found in various marine animal oils as shown in the two preceding papers. The bromine content of the bromide of the acid was just the same as that of octa-bromo-stearidonic acid to which we referred already in Part $V$, but the melting point of the two acids differs, on the other hand, quite markedly (octa-brobmostearidonic acid: $200 \mathrm{C}$. decomposed; the bromide of the new acid: $105 \mathrm{C}$ ), demonstrating that the two acids cannot be identical. The melting point as well as the elementary composition of the saturated acid obtained by the debromination and hydrogenation of the bromide of the new acid, had shown that it is stearic acid. The new acid, therefore, is an isomeride of stearidonic acid, differing from this, perhaps, in the positions of ethanoid linkages.

\section{EXPERIMENTAL}

$\mathrm{C}_{22} \mathrm{H}_{38} \mathrm{O}_{2} . \quad 1330 \mathrm{~g}$ of sardine oil, in petroleum ether, was brominated as usual. The solid, insoluble bromo-glycerides was treated with several solvents in the order of ether, benzene, acetone, pyridine and acetic ester, the acid in question being contained in ether as well as acetone fraction. The combined yields of the two fractions were $63.3 \mathrm{~g}$. The glycerides were hydrolysed by boiling with ten parts of hydrochloric acid $(20 \%)$ for several hours. The products of the hydrolysis were extracted with 
benzene, the bromide of the new acid being soluble in the solvent. Recrystallysing several times from the same solvent, the pure acid was obtained to the extent of $8.1 \mathrm{~g}$ as bromide. M.P. : $96^{\circ} \mathrm{C} ., \mathrm{Br}: 65.75 \%$ $\left(65.80 \%\right.$ as $\mathrm{C}_{22} \mathrm{H}_{36} \mathrm{O}_{2} \mathrm{Br}_{8} ; 65.71 \%$ as $\left.\mathrm{C}_{16} \mathrm{H}_{26} \mathrm{O}_{2} \mathrm{Br}_{6}\right)$.

The pure bromo-acid was debrominated with zine dust in a suspension in acetic acid, and the resultant unsaturated acid was hydrogenated with hydrogen gas in the amyl alcoholic solution in the presence of platinum black. Lead soaps of the hydrogenated products were formed in their turn by the usual method and the easier soluble portion was removed by extracting the soaps with ether. The pure saturated acid, formed by hydrolysing the soap with hydrochloric acid and recrystallising from alcohol, melted at $78 \mathrm{C}$. C: $77.55 \%, \mathrm{H}: 13.37 \%(\mathrm{C}: 77.57 ; \mathrm{H}$ : 13.03 as $\left.\mathrm{C}_{23} \mathrm{H}_{44} \mathrm{O}_{2}\right)$.

$\mathrm{C}_{18} \mathrm{H}_{28} \mathrm{O}_{2 \cdot}$. In the benzene soluble portion of the same brominated sardine oil, $55.7 \mathrm{~g}$ of a bromo-glyceride which contained $\mathrm{C}_{18} \mathrm{H}_{28} \mathrm{O}_{2}$ were found.

The procedures adopted after the glyceride was separated were the same, in general outline, as in the preceding case.

The brominated acid: M.P.: 104-105 C. ; Br: 69.38\% (69.84 as $\left.\mathrm{C}_{18} \mathrm{H}_{2} \mathrm{O}_{2} \mathrm{Br}_{8}\right)$.

The saturated acid: M.P.: $71 \mathrm{C}$. (was not depressed on mixing with pure stearic acid); C: $76.01 \% ; \mathrm{H}: 12.63 \%$ (C: $75.98 ; \mathrm{H}: 12.76$ as stearic acid).

Our sincere thanks are due to the Department of Education, Imperial Government, which provided a part of the expenses of this study. 